\title{
The Work of Milgrom and Wilson in the Theory and Practical Application of Auctions*
}

\author{
Péter Biró - Gyula Magyarkuti
}

This paper seeks to provide insight into the field of auction theory to the general readership, the area of the 2020 Nobel laureates in Economic Sciences, Paul Milgrom and Robert Wilson. To understand for what reasons and for what purpose they were awarded the Nobel Prize, it is worth taking a step back, looking at this area of economics from a greater distance. For this reason, we not only report the results associated specifically with their names here, but we also review the path to get here. Finally, we provide an outlook for the future of the topic with a brief description of the interdisciplinary areas of engineering economics and market design.

Journal of Economic Literature (JEL) codes: C78, D44, D47

Keywords: auction, game theory, mechanism design, market design, engineering economics

\section{Outlook}

Milgrom and Wilson received the 2020 Nobel Prize in Economics for advancing the theory of auctions and developing new auction procedures. Wilson was the doctoral advisor for Milgrom's PhD at Stanford, and Milgrom is now Wilson's third Nobel Prize-winning student after Roth (2012) and Holmström (2016). This recognition has long been expected by the profession, and Milgrom's work, with more than 100,000 references, is outstanding among theoretical economists.

Numerous summaries and laudatory articles have been published on the work of the two laureates in recent months. One of the aims of our summary is to present the work of the winners and the topic of auctions to Hungarian readers. Another one is to provide a mathematically founded introduction to auction theory in addition to the summary in the official scientific background report, and to analyse

* The papers in this issue contain the views of the authors which are not necessarily the same as the official views of the Magyar Nemzeti Bank.

Péter Biró is a Senior Research Fellow at the Institute of Economics of the Research Centre for Economics and Regional Studies. Email: biro.peter@krtk.hu

Gyula Magyarkuti is a University Docent at the Mathematics Department of the Corvinus University of Budapest.Email: magyarkuti@uni-corvinus.hu

Péter Biró thanks the National Research, Development and Innovation Office for its support through Hungarian Scientific Research Fund (OTKA) project No. K128611.

The Hungarian manuscript was received on 17 January 2021.

DOI: http://doi.org/10.33893/FER.20.1.127151 
in more detail the new interdisciplinary fields of engineering economics and market design that include auctions.

We encounter auctions in situations where neither the seller nor the buyer knows at what price it would be worthwhile to conclude a transaction. Of course, both the seller and the buyer can imagine an amount which is small enough or large enough that they think will already make an adequate profit, but it is rather questionable whether the demand and supply generated in this way will meet. In such a situation, organising an auction can be a way out.

The naturalness of this idea is also reflected by the fact that we can find very ancient examples of it in human culture. Here are just three examples that are at least 2,000 years old. One of the oldest references in the literature mentions the Greek historian Herodotus: Krishna (2002) gives a detailed description of the way in which an assignment for marriage between women and men was created in ancient Babylon. In the Bible, according to Matthew 27:35: "And they crucified him, and parted his garments, casting lots..." In our interpretation, the term "casting lots" here does not imply a query of God's will, but rather the appearance of an auction-in addition a multi-object one-on the specific course of which we do not receive information here. Our third example also relates to the Roman Empire. There is written record that the Roman Empire's state administration routinely used auctions. Shubik (2004) notes that in one case of Cicero, in 80 BC, his client's property, which the client offered as a guarantee in another transaction, had to be auctioned. At the time, it was customary to confiscate debtors' property and then auction it off. Sulla extended this even to the assets of his political opponents, thus liquidating his opposition and at the same time generating huge revenue for the treasury. Ovid records in $10 \mathrm{AD}$ that it is worth releasing the state from the burden of collecting taxes by auctioning the right to collect them. To give an overview of ancient auctions is far from the purpose of this essay. For readers interested in the topic, we recommend the very interesting work by Shubik (2004) Section 8.1.2. According to Nobel Prize Committee (2020), the oldest auction house still operating today is the Stockholms Auktionswerk, founded in 1674.1 Sotheby's in London or Christie's in New York, known to almost everyone, are the two largest art auction houses. For many people, the concept of today's auction is confused with Sotheby's or Christie's fine art treasure auctions, which is incorrect and misleading. The volume of fine art treasure auctions accounts only for a negligible share of the volume of all auctions. In general, it may be said that auctions have never been as important a slice of economic activity as they are today. Fish, fresh flowers and diamonds are traditionally marketed through auctions. Similarly, a bond issue is a special auction, and from mining rights to the auction of mobile phone frequencies

${ }^{1}$ By clicking on the link http://auktionsverket.com/, you can immediately bid on something or even sell something. 
all are examples where conducting an auction guarantees a deal, i.e. an auction is used to select the winner and determine the price of the product. In the 21st century, the concept of online auctions has become quite important. A huge amount of things are sold and bought on the eBay platform, for example. Considerable EU grants are also auctioned. For example, the state aid for the establishment of solar farms, among renewable energy subsidies, in Germany has been distributed via multi-object auctions for years. The products are subsidies given to individual producers, and the bids are the estimated costs of the applicants. Of course, this is a reverse auction in the sense that, for example, the aid for 20 products, i.e. 20 solar farms, will be won by the first 20 lowest bidders in the order. For details, see Kácsor (2021).

The latter example also shows that the concept of auctions is worth considering in a rather abstract way and that applications may emerge that at first seem quite distant from the layman's concept of auctions. Just for the sake of provocation: a simple lottery game is also an auction. The role of bids is played by the number of lottery tickets purchased, and the winner of the auction is the one whose ticket is drawn. More importantly and interestingly, the order of the ads built into Google's search engine is determined by the results of a multi-object auction running in real time when searching (Edelman et al. 2007). We write about this in more detail later.

\section{Auction Theory}

The question arises as to what we mean by auction theory. The answer can be summarised in the following two questions.

- How do bidders behave in the case of different auction formats under different auction conditions?

- How can the auctioneer choose the auction format and playing rules that best suit its goals?

To approach the first question, we need to understand what forms of play may arise, and for the second question, we need to see that the purpose of the auctioneer can be quite varied. It is possible that it wants to maximise its profits, but it is also possible that the goal is to achieve optimal social well-being.

As compared to physics or engineering for example, one generally accepted disadvantage of economic theories is the lack of experiments. Just think of macroeconomic problems, the theory of money, or equilibrium theory. Many times we feel that abstractions and results that are beautiful in themselves would be complete if some experimental realisation of them could be provided. By contrast, it is common experience that we can come to conclusions about the operation of 
the economy that are contrary to the theoretical results. In our view, auction theory plays a rather prominent role in this matter. Every single auction actually played out is, after all, an experiment of theory. In this way, the much-desired verification becomes possible. Furthermore, in addition to observing real markets, the use of laboratory experiments with human decision-makers in the field of experimental economics has intensified in recent decades, proving to be particularly useful in auctions, see for example (Kagel et al. 2010).

In this regard, it is also worth thinking about the work of the Nobel laureates honoured here. The radio-spectrum auction (CCA) they constructed was used in the UK in 2008, and then the frequency rights of Austria, Australia, Denmark, the Netherlands, Ireland, Canada, Romania, Slovakia and Switzerland were sold using essentially the same technique (see Nobel Prize Committee 2020). Of course, for the governments of the countries in question, the goals of the spectrum sales are the most important, but as a by-product, the theory created by the Nobel laureates has also gained practical verification, providing an example for the practical application of rigorous scientific theories.

Paul Milgrom is 73 years old, Robert Wilson is 84 . It is clear from their ages that their recognition is the recognition of their entire scientific career, but not only that. The decision of the Nobel Prize Committee is seen by the profession as the setting of direction for further development as well. Of course, the relevance of this is debatable, but if we look back at the Nobel Prizes in economics of the last century, this idea is strongly confirmed. In their case, the question then also arises as to what the message of their Nobel Prize is to the scientific community. In our view, the answer is very simple and clear: shifting economics towards engineering. Think about what the state does when it wants to build a major public bridge. A firm of architects is commissioned and the expectations regarding the bridge is communicated to them. The engineers in the architecture office then work out a state-of-the art plan and even a construction plan that ultimately defines the construction process down to the smallest screw. Accordingly, the idea that, in an imagined brave new world, if the state needs spectrum auctions in the public interest, for example, it should be able to turn to a community whose members are able to define the best form of auction based on scientific principles, and not only define it, but design it down to the finest details.

\subsection{The simplest standard auctions}

To approach the results of Milgrom and Wilson, it is worth starting with the simplest auctions. We speak of a standard auction if the highest bid wins, i.e. the player with the highest bid receives the object of the auction. Examples of non-standard auctions are any auctions that use a reservation price or a lottery game. The simplest and also the most popular standard (single object) auctions are: 


\section{Dutch or clock auction:}

The announcement starts at such a high price at which it is not worth obtaining the object of the bid for any of the bidders. The price is gradually reduced in small increments until it becomes just right for one of them. The bidder indicates this, for example, by a show of hands. This ends the auction, and the winner of the auction, i.e. whoever obtains the item, is the player with the raised hand, who has to pay the price that was valid when the game ended.

Using this method, more than 20 million flowers are marketed in the Netherlands every day, which is why it is called the Dutch auction. Federal Reserve bonds are also issued using a similar auction (see Nobel Prize Committee 2020:7). In connection with bond issues, we also recommend Monostori's (2013) review.

\section{English auction:}

In contrast to the previous one, the auction starts at such a low price that many bidders would buy the object of the auction at that price. The price increases gradually, in small enough steps. If the price becomes so high that it is no longer acceptable to a player, the player in question will withdraw from the auction. They indicate this by lowering their hand, for example. The auction ends when there is only one bidder left in the game. The winner of the auction is the only bidder, and it will have to pay the going price at the end of the auction.

The root of the word "auction" may come from the Latin verb "augere" (increase) suggesting that the English auction may have been known in the Roman Empire as well. Art auctions, also known from films, such as the auctions of the Sotheby's auction house, also work in this manner. This is why it is called an English auction.

\section{First-price sealed-bid auction:}

Bidders place their bids in a sealed envelope, which means that the players in the game have no information about each other's bids. And with that, the auction ends. After the opening of the bids, the bidder making the highest bid is the winner of the auction, so it will obtain the object and has to pay the amount of its bid.

\section{Second-price sealed-bid or Vickrey auction:}

This form is identical in all respects with the first-price sealed-bid auction, except for the obligation to pay. The winner of the second-price sealed-bid auction is not obliged to pay its own bid, but the highest losing bid, i.e. the second highest of all bids.

It is a textbook case that the dominant equilibrium strategy of this auction is truthtelling, i.e. rational bidders in this auction bid with their own valuation. 
Let us examine the above four auctions based on the following criteria:

1. Who wins?

2. Who pays what?

In the above auctions, the object is won by the player with the highest bid placed in one way or another, and they are always the only one to pay. Losing bidders pay nothing. The obligation to pay is the value of the highest bid submitted in one way or another in the case of the Dutch and the sealed-bid first-price auctions, while it is the value of the second highest bid arriving in one way or another in the case of the English and the second-price auctions.

Therefore we see that, from this point of view, the Dutch and the sealed-bid firstprice auctions belong together, and similarly, the English and the second-price auctions are related. The question is whether we can consider the Dutch auction to be exactly the same as the closed-bid first-price auction, and by analogy that the English auction is the same as the closed-bid second-price auction.

\subsection{Information content of evaluations}

We assume that the players are rational, they have some evaluation of the object of the auction, and their bid is based on that evaluation. How the valuation can take shape is well illustrated by the information gap between the English auction and the second-price auction. In the English auction, the exiting players will gradually announce their bids. In the end, only the exact value of the winning player's bid remains a secret. Of course, no information will be revealed during the process of the second-price sealed-bid auction.

If we compare the Dutch auction with the first-price, sealed-bid auction, we find a difference in information there as well, but this difference is not as severe as in the case above. During the process, everyone has at least an upper estimate of the other players' bids, but that is the entire difference. When the Dutch auction ends, the exact bid of the winner is revealed, but this is too late for the other players as the auction is just coming to an end.

The question is whether or not this information difference is incorporated into each player's valuation. Based on this, we differentiate the valuations:

\section{Private values:}

When the participants, regardless of the influence of others, know how much the product is worth to them. By this we mean that none of the players knows - and moreover they are not even interested in - the other players' evaluation of the object of the auction. 
This typically occurs when the usefulness of the auctioned item comes solely from the consumption of the item. Our initial impression is that there may be very few such auctions. Art auctions or bond issues, for example, are very far from this, as the usefulness of an object is also influenced by the secondary market, and thus the present value depends on the future valuation of others.

Note that in practice, a really relevant case may be included here. For example, the most important factor in the evaluation of support for solar farms for a landowner is the number of hours of sunshine on their land. This valuation is not affected in any manner by the valuation of the owner of another farm which may be hundreds of kilometres away.

It is also worth seeing that the auction of spectrum frequencies is similar to this, and yet it is not. Obviously, there is a private valuation aspect, since, for example, the necessary technological tools are available to everyone in much the same way and market demand can be estimated in an exact way, but the value of each frequency band depends very much on the frequencies of neighbouring areas and thus on the possible outcomes of other auctions. In addition, bidding companies may have a different range of service-providers and business strategies, so a spectrum package may have different utilisation values for them.

\section{Common values:}

When it is not about a private value auction. This is the case where the evaluation depends not only on the item auctioned itself, but also on the opinion of the other participants about it. Typically, this is the case of an assessment where the value of the item depends on a value that develops in a possible secondary market. The evaluation of oil fields, for example, is certainly like this. It is impossible to know the exact capacity of an oil field, and estimating it is also very expensive. In this way, all of the information obtained about the capacity is extremely valuable, and thus by expressing their valuations, the parties involved in the game influence each other.

We can say that under the assumption of private values, the first-price sealed-bid auction can be identified with the Dutch auction, and similarly, we also make no distinction between the second-price sealed-bid auction and the English auction. This is called strategic equivalence, by which we roughly mean that if the same players played the two types of auction with the same values, the winner's identity and the auctioneer's revenue would be the same in both auctions.

\subsection{Private values}

The revenue equivalence principle is the basis of the theory of private value auctions. Auction theory research in recent years has been motivated by the violation of this. The point of the idea is that assuming strictly private valuations, under sufficiently broad conditions, the payment of players does not depend on the 
specific construction of the auction; for details, see Krishna (2002) or Magyarkuti (2018) in Hungarian.

Theorem (revenue equivalence principle): Suppose that a standard auction conducted in a symmetric model with private values is played by risk-neutral parties with a strictly monotone increasing bidding function in a symmetric Nash equilibrium situation.

At this point, each player's expected payment function is independent of the structure of the auction and can be written independently of the Nash equilibrium bidding function used.

Thus, the auctioneer's expected revenue does not depend on the bidding functions that guarantee Nash equilibrium, nor does it depend on the structure of the auction.

Each player knows their own evaluation, but for the outside observer, the players' evaluations are the realisation of a random variable. Let these be $X_{1}, \ldots, X_{N}$ with the same $F$ distribution. The assumption of private values implies the independence of these random variables. We assume that all players use the same $\beta$ Nash equilibrium bidding function. Since the betting function gives a one-to-one correspondence between possible bids and evaluations, the player with the highest evaluation wins, so the probability of winning with evaluation $x$ is $G(x)=F^{N-1}(x)$. Similarly, since everyone uses the same bidding function, the expected payment of each player depends only on their valuations. We denote this by $m(x)$. Then the equilibrium profit is $G\left(x_{0}\right) x_{0}-m\left(x_{0}\right)$ with a given $x_{0}$ valuation and the corresponding $b_{0}=\beta\left(x_{0}\right)$ equilibrium bid. But if our player indicated bid $b$, with the others still using the $\beta$ bidding function, then its expected profit would change to $G\left(\beta^{-1}(b)\right) x_{0}-m\left(\beta^{-1}(b)\right)$. According to the concept of the Nash equilibrium, this means that with a given $x_{0}$ evaluation the function:

$$
b \longmapsto G\left(\beta^{-1}(b)\right) x_{0}-m\left(\beta^{-1}(b)\right)
$$

at point $b_{0}=\beta\left(x_{0}\right)$ is at a maximum, and thus its derivative is zero here. Let us denote the derivative function of $G$ by $g$, and accordingly the derivative of the above factorised right side will be: $g\left(\beta^{-1}(b)\right) \frac{1}{\beta^{\prime}\left(\beta^{-1}(b)\right)} x_{0}-m^{\prime}\left(\beta^{-1}(b)\right) \frac{1}{\beta^{\prime}\left(\beta^{-1}(b)\right)}$. The value of this at $\beta\left(x_{0}\right)$ will be zero, ergo $\mathrm{m}^{\prime}\left(x_{0}\right)=\mathrm{g}\left(x_{0}\right) x_{0}$. Of course, this is true for every evaluation, so according to the fundamental theorem of calculus, for every possible $x$ evaluation

$$
m(x)=\int_{0}^{x} g\left(x_{0}\right) x_{0} d x_{0},
$$

assuming that we allow that with zero evaluation the player has no cost, that is $m(0)=0$. And we are ready, since $m$ depends only on $g$ which is given by the distribution of the random variables describing the valuations. The expected payment $m$ therefore does not depend on anything else. Of course the expected 
revenue of the auctioneer is $\sum_{j=1}^{N} E\left(m\left(X_{j}\right)\right)$, since the entire revenue of the auction comes from the bidders. We have thus obtained that the expected revenue for each such auction is the same amount, regardless of the specific structure of the auction.

Specifically, first-price, second-price, everyone-pays or only-losers-pay auctions in such circumstances result in the same expected revenue for the bidder.

Without getting lost in details, the most important assumption of the above train of thought is the independence of the random variables describing the valuations, that is, the assuming of private values. The event $\left(X_{2}<x\right) \cap\left(X_{3}<x\right) \cap \ldots \cap\left(X_{N}<x\right)$ means, for example, that the evaluation of the first player is the highest. The reason why the probability of this event is $F^{N-1}(x)$ is independence, so $G(x)$ is the probability of winning of a player with evaluation $x$ in a standard auction. There are much more general known versions of the revenue equivalence principle explained above, also for multi-object auctions for example, but the point is the assumption of private values.

One important consequence of the revenue equivalence principle is that it makes it possible to describe the behaviour of bidders under different forms of auction. For example, in a first price auction, $m(x)=G(x) \beta(x)$, since the expected payment is the probability of winning multiplied by the payment obligation in the case of winning, which is the current bid in a first-price auction. Here, as before, the Nash equilibrium bidding function is $\beta$. From this and the above, the Nash equilibrium bidding function of the first-price auction is immediately derived:

$$
\beta(x)=\frac{1}{G(x)} \int_{0}^{x} g\left(x_{0}\right) x_{0} d x_{0} .
$$

Without going into the mathematical details here, the Nash equilibrium bidding function of an arbitrarily structured auction arises similarly. It is worth noting that in a second-price auction rational players use the identity (truthfulness) bidding function; in the first-price auction the above highlighted bidding function always results in a lower bid than the evaluation, but in a third-price auction we get higher bids than the evaluation.

\subsubsection{War of attrition}

Here we would like to draw attention to the fact that understanding the behaviour of the parties participating in auctions can lead to interesting results even in areas far from economy. To illustrate this, a nice example is the analysis of the war of attrition auction in Milgrom's book (Milgrom 2004) - considered a fundamental work. The definition of the simplest case is as follows: We only have two players, the winner is the player with the higher bid. The winner takes the object of the auction and both players pay the losing, i.e. the smaller bid. At first glance, we may feel that this auction is exotic, but then we may notice that mankind plays out such 
auctions in varied and very unfortunate situations, so the conclusion may be that such situations should be certainly avoided.

Milgrom's interpretation is as follows. Two hungry beasts are facing each other. What they are bidding with is the work invested to get the food in front of them. By this we can mean the loss of energy caused by the fight, or the (negative) usefulness of the injuries caused by the fight, or simply the amount of time spent getting the food, i.e. the length of the fight. Clearly, the loot is taken by the one who gives up later, but they both pay for their investment in the battle. So, the war of attrition auction really models the conflict.

Following the previously introduced formalism, using the revenue equivalence principle, we obtain that the Nash equilibrium bidding function looks like this:

$$
\beta(x)=\int_{0}^{x} \frac{g\left(x_{0}\right) x_{0}}{1-G\left(x_{0}\right)} d x_{0} .
$$

Considering that with high $x_{0}$ evaluations the denominator tends to zero, so it appears that the Nash equilibrium bidding function of the war of attrition auction tends to infinity for a sufficiently wide range of distributions when the evaluations tend to the highest possible value. We see then that the rationality of the parties in the war of attrition auction - since this is a matter of Nash equilibrium - is, unfortunately, that irrationally high bids are placed. Hence, the conclusion that these conflicts should be avoided. An unfortunate historical example of the failure to avoid a war of attrition auction situation is the Maginot Line built after World War I or the Battle of Stalingrad in World War II.

\subsection{Common values}

As noted earlier, we speak of common values when bidders do not formulate their evaluation independently. The first phenomenon we need to understand is the so-called winner's curse.

Consider the following thought experiment: We auction an object of roughly equal value to players who pay close attention to each other and base their evaluation not only on the usefulness of consuming the object, but also place great emphasis on incorporating information from the evaluation of others into the value of the object. Of course, none of the bidders can pinpoint the exact value of the item, they only estimate it. We can express this by assuming that each player puts a white noise from, for example, the normal distribution on their own original evaluation. This will be their estimate, and then the evaluation of neighbouring players will be based also on this. But not only on this, also on their own evaluations, independent of the others, on which they also put their own white noise, and so on, for every participant in the auction. Under such circumstances, if the ownership 
of the object really gives everyone a similar utility, then the average of the values may be the closest approximation of the true value. This means that in a standard auction, it is definitely bad news for the winner that he won, as he is the one who deviated the most from the average, i.e. he closes a first-price auction probably with a negative profit. We also see that as the number of players in the auction increases, overvaluation becomes more severe. This is called the winner's curse. It is very important to emphasise that we never talk about a winner's curse in the case of private value auctions, as there the other bidders have no influence on the current valuation.

The winner will therefore certainly overestimate the value of the item. Players, on the other hand, think rationally, which specifically means that they are able to understand the above idea, so another twist is added to the story. So they know that the winner who comes out of them overestimates the object. Therefore, they strive to avoid the resulting overvaluation, so that this fact is also built back into the formulation of their valuation. The consequence of this may be that the auctioneer will not receive the true value of the object.

Milgrom and Weber (1982) analysed the revenue of the four simplest auctions with common values. They came to the result that under the same circumstances the highest average revenue comes from the English auction, less comes from the second-price sealed-bid auction, and, finally, the Dutch and the first-price auctions yield the third highest revenue. In this regard, we note that the strategic equivalence between the Dutch auction and the first-price sealed-bid auction still exists. It can be seen that the highest valuation only becomes known when the Dutch auction is about to end, so the parties to the auction cannot use this additional information.

Looking ahead to the FCC auctions to be detailed later, we can conclude that the loss of revenue caused by the winner's curse can be mitigated by sharing as much relevant information as possible with the bidders. This is the so-called linkage principle. The idea is that the reason why in English auction players can filter out disturbing effects more efficiently also from their common values is because they gain more and more information as individual players reveal their evaluations. Later, this idea will be seen echoed in the famous frequency auctions where a slower, preferably multi-round auction format is used, which forces the players to reveal their real evaluations, with the result that the winner's curse effect is reduced.

\section{Multi-object auctions and related applications}

So far we have investigated single-object auctions. In real markets, however, auction procedures are becoming more common even in more complex cases where a buyer wants to buy a larger quantity of a product or several connected products at the same time. In this chapter, we introduce this topic. 


\subsection{Divisible objects}

If one or more sellers want to sell a large quantity of a homogeneous product to several buyers at the same time, we speak of a so-called share auction. The earliest application for this is the market for claims or public debts, but energy markets (Wilson 2002), or, say, the market for fishing rights (Bichler et al. 2019) can also be mentioned and linked to the work of the Nobel laureates as well.

In Wilson's pioneering article (Wilson 1979), he examined a model where customers could also give their valuations for certain parts of a divisible object. He examined two types of auctions. In one case, the common price is a condition, while in the other, the customers are allowed to pay different prices for the same quantity of products according to their offers. It was shown that, compared to single-object markets, market participants have even more incentives to bid lower than their actual valuation and are even more able to push down equilibrium prices through coordination. In Hungary, for auctioning government securities, the replacement of discriminatory pricing by uniform pricing was raised following the Polish example (Monostori 2013). In a later study (Wilson 2002), Wilson discussed modelling problems related to the energy market in detail, on some of which he presented theoretical results later (Wilson 2008).

\subsection{Multi-object one-to-one auctions}

In this section, we briefly discuss the special case where customers can bid on more than one object at a time, but each buyer wants to buy only one of the several options. Then the problem still remains tractable, and we give an example of this in connection with the auction of online advertising space.

The job market is a simple but important example for this type of market, where employers typically advertise one job and employees look for one. For the gametheoretic description of this market, the assignment game (Koopmans - Beckmann 1957; Shapley - Shubik 1971) is the best suited one, where players can form pairs and share the benefits among themselves. A stable (or core) solution always exists, and among the stable solutions there are two extreme ones that give the best solution to all the actors on one side or the market or the other. If an auction provides, say, an optimal solution for buyers, then the mechanism cannot be manipulated by buyers, i.e. everyone's best strategy is to give their true valuation as a bid.

The assignment game is a good approximation for the labour markets (Fox 2018), but auction solutions are not used here at all due to the decentralized nature of the market. In the case of the sale of online advertising space, however, the task is similar, and algorithmic auctions are widespread there. A significant example of this is presented below. 


\subsubsection{The keyword auction of Google}

Billions of searches are done on Google every day, and each time there is an algorithmic auction running in the background that determines which buyers' ads will appear as paid ads in the possible 4-5 places on the user's page. 90-95 per cent of Google's revenue comes from these types of keyword auctions, which means that huge amounts of money are involved. One of the great benefits of online advertising is that it is personalised, as the service providers (Google, Facebook, etc.) can have important information about the user who is searching or browsing and can therefore sell the ads in a personalised way at the user interface. The other technological advantage is that the result of the advertisement can also be measured well with the help of cookies, and thus the billing towards the advertising companies is more accurate. You can pay for an impression, for a click, or for a completed transaction. Google uses the pay-for-click version to auction keywords.

Considering the nature of the auction, the assumption that each buyer wants to buy at most only one advertising part on the site is fulfilled, so in theory the buyeroptimal solution of the assignment game can be applied, which has actually been analysed (Aggarwal et al. 2009; Dütting et al. 2013). In contrast, the solution used by Google has been a simpler general second-price mechanism (Edelman et al. 2007). The bottom line is that the best, first, ad slot is given to the buyer who bids the most, but they only have to pay the second bid. The second buyer pays the third bid, and so on. More specifically, they look not only the bids, but also the relevance of the ad for that particular keyword and user, a metric of which is multiplied by the buyer's bid, thus forming a ranking of the buyers. The price paid by the winning customers means a price sufficient to maintain the ranking.

This auction is not strategy-proof because it is possible to give an example when a buyer has to pay significantly less, say, for the 3rd place than for the 2nd one, even though it is not worth much less to them (see for example in the Haeringer 2018 textbook). However, the current design has a number of advantages. For example, it encourages companies to advertise relevant content, making customers more satisfied, and generating more revenue for Google especially because they receive the payments for clicks. It should also be said that ads are typically ordered by companies in complex campaigns rather than individually, meaning that the small strategic profits at each auction are negligible compared to the fact that the companies can run a well-organised, and measurably efficient campaign with predictable costs on Google's platform.

\subsection{Indivisible, interrelated products}

If a buyer can buy more than one product for which there are complements in their valuation, the auction problem becomes much more complex. For this case, we first present VCG auctions, which have good theoretical properties, but there 
may be several problems in their practical application. One of Milgrom and Wilson's most important practical works is the FCC's 1994 spectrum allocation auction (Bichler-Goeree 2017), which is based on a simultaneous multiple round auction (SMRA, or simultaneous ascending auction, SAA). An improved version of this is the combinatorial clock auction (CCA), where buyers can also bid on packages. We conclude the chapter with an introduction to the so-called Incentive Auction, first used in the 2017 FCC auctions, where the frequencies of radio and TV operators were first bought centrally and then, after re-allocating the remaining frequencies, the freed bands were sold to mobile operators.

Now, what is the challenge in multi-object auctions? Take a simple case that the Nobel laureates also mentioned in their lectures. Suppose the spectrum is auctioned simultaneously in Northern and Southern California. There may be a company that is only interested in buying a frequency in the South, but there may also be another that wants coverage for the entire state for its service and therefore a license for only one region is worthless for them. If spectrum auctions are announced for the entire USA, those interested in much more complex packages will also appear.

An allocation is said to be efficient if the combined valuation of the customers is maximal. This is a basic requirement for the solution, but the revenue received by the seller is also an important consideration especially when it comes to government revenues, so it also plays a role in pricing. However, the mechanism should continue to encourage buyers to disclose their true valuations, ideally in a strategy-proof way, but approximately real or well-estimated bids may also be satisfactory when evaluating the auction results. Finally, an important aspect is the simplicity of the mechanism. In many cases, it is impossible to request the full value function of customers, as they would potentially have to provide it for an exponentially increasing number of packages in the number of products. One possible treatment for this issue is to pre-select relevant packages, or use iterative procedures where customers only give bids for packages that are realistically available to them.

What are the possible problems and solutions? Consider the following simple example: There is an apartment and a garage that the owner wants to sell in an auction, either together or separately. Three interested parties arrive, buyer $A$ is only interested in the apartment, he would give 43 million forints for it, buyer $B$ only interested in the garage, and he would buy it for a maximum of 12 million, and buyer $C$ would buy the two for 50 million, but only together. The efficient allocation in this case is when buyer $A$ gets the apartment and buyer $B$ the garage. But how can an auction achieve this efficient result, and most importantly, how much should the buyers pay? 


\subsubsection{VCG auctions}

The Vickrey-Clarke-Groves (VCG) auction is based on three classic papers: Vickrey (1961), Clarke (1971) and Groves (1973). Among them, Vickrey's work was also recognised with a Nobel Prize in 1996. In the case of a multi-object auction, it works as follows: Each buyer can bid on any package of objects. The allocation of the solution will be efficient for the bids as well as for the valuations, as it can be seen that the mechanism individually incentivises each customer to tell the truth. The price is defined as follows: each customer pays as much for their package as much the overall utility of the other customers is reduced by removing that package from the product set.

In the previous example, buyer $A$ will pay 38 million, as the two objects are worth a maximum of 50 million to the other buyers (this is the case if both objects are received by buyer $C$ ), while without the apartment, the remaining set of objects (which is merely the garage) is worth 12 million for buyer $B$, so the difference between the two will be the price for buyer $A$, that is, 38 million. Similarly, it can be calculated that buyer $B$ will have to pay 7 million for the garage. The total revenue of the seller is therefore 45 million.

The VCG auction operates also in a much more general framework than multi-item markets, and its main feature is that the best individual strategy for each buyer is to provide true valuations. It follows that solution allocation is always efficient for true valuations. In practice, however, VCG auctions are not used in many applications, for several reasons. On the one hand, it can generate low revenue for sellers. In the example above, if customer $C$ leaves, then both $A$ and $B$ will receive the evaluated item for free. This problem can be partially avoided with minimum prices. The other problem is that the buyers can cooperate and get a better price. In the example, if $C$ reduces his bid, the other two buyers will be better off because they have to pay less and may be able to share that benefit with each other afterwards. In larger markets, even the calculation of efficient allocation can be difficult, as this is an NP-hard problem for complementary products, i.e. no fast algorithm is expected to compute the solutions. This is a considerable problem also because the use of approximate solutions can be not only suboptimal for the final allocation, but it can make also pricing very inaccurate.

However, there are applications such as one-to-one auctions and their minimal generalisations for which VCG still works well. One famous example of this is the auction of Facebook advertising space (Varian - Harris 2014). In the more complex markets, as an alternative to VCG, simultaneously-ascending-price auctions based on a relatively simple principle appeared in more and more applications in the 1990s. One of the most significant of these was the spectrum market which is described in the next section. 


\subsubsection{Spectrum auctions}

Licenses to use the radio frequency spectrum have previously been allocated among applicant companies by government decision or simple lottery. From the 1980s onwards, the use of auctions became more widespread. On the one hand, national governments recognised that they could generate high revenues from this. On the other hand, market price competition, if used properly, also ensured that companies that could generate the greatest social and economic benefits from this finite resource received the rights. Designing spectrum auctions has become a priority task for auction theorists, resulting in extensive research and successful applications (Bichler - Goeree 2017).

The US Federal Communication Commission (FCC) is responsible for regulating the US radio frequency market. In 1994, as proposed by Milgrom, Wilson, and McAfee, it was implemented through an ascending-price simultaneous auction (SMRA), which generated even more revenue than expected and then it spread to many countries around the world (Bichler - Goeree 2017). The essence of the procedure, which was analysed in detail by Milgrom (2000), is that bids can be received in several rounds, iteratively, and after the last active round, each item is given to the buyer who offered the most, and the price equals the final bid.

In the example above, all three buyers would certainly actively raise their bids until the combined price of the apartment and garage reaches 50 million forints, say, at 40 million for the apartment and 10 million for the garage, where buyer $C$ exits the auction. We can see that we get the same efficient allocation, but the seller's revenue here will be higher than in the VCG auction.

What are the advantages and possible disadvantages of the method? It is definitely simpler and more transparent than VCG; the buyers only have to make an offer in response to the given prices, so they do not have to give the valuations on all the possible packages, the prices contain all the relevant information. It is expected to generate more revenue for the seller than VCG. Finally, under certain conditions, the final allocation remains efficient, for example, in the absence of complements, in the case of substitute products, assuming straightforward bids from the customers (Milgrom 2000).

Among its disadvantages, manipulation by demand reduction and the exposure problem can be pointed out, which are presented in more detail below.

The exposure problem can be illustrated in our example as follows. Let us suppose that players $A$ and $B$ are now the same first player, so he would either buy just the apartment for 43 million forints or just the garage for 12 million, but he does not want to buy both. Player $C$ does not change, he will be the second player. In this case, following their real valuations, the prices start to rise again, the first 
$(A+B)$ player always bids on only one item, and for the second $(C)$ player it is worth matching the bids until the combined price reaches HUF 50 million. When, on the other hand, it reaches that, e.g. at a price of 40 million and 10 million, he faces the following problem: he is leading with his bid only on one item, and this single item is worthless for him in itself, i.e. if the auction stops, he will realise a big loss. Therefore, he will be forced to continue bidding, to reduce his loss, even if the total price already goes over 50 million forints. Buyers who prefer larger packages are therefore exposed to the fact that, in the end, they may not get full, valuable packages or may have to pay more than their real valuation to obtain them, and thus suffer a loss.

Regarding demand reduction, let us imagine that in addition to the previous first $(A+B)$ player, for the second player $(C)$ now, in addition to the 50 million apartment + garage pair, the apartment alone is also worth $\mathbf{3 8}$ million. This, truthfully following the real valuations in bidding, leads to the result that the first player buys the garage for 12 million, while the second player buys the apartment for 38 million, so neither of them realises a profit. If, on the other hand, the second player gives up the apartment and garage pair and does not bid on the garage at all, the garage will go to the first player for a minimum price of 1 million, and in return the second player will not go over 32 million for the apartment, since his gain would not be higher than in the case of the garage (12-1 million). That is, by reducing his demand, the second player achieved that the first player was satisfied with the garage, so he was able to get the apartment at a better price, and both of them were better off by this manipulation.

A third problem with ascending auctions is that there may be a buyer who waits till the very end, and then, in the last round, knowing the prices, takes the packages that are most favourable to him, leaving the others high and dry; this action is called sniping.

How can these problems be prevented in practice? The exposure problem is most severe when there are significant complementarities between products, and the value of a product package is much higher for customers than the sum of their subvalues. This issue can be avoided by a combinatorial auction, a version of which is the combinatorial clock auction developed by Milgrom and others (Ausubel and Milgrom 2002). For some applications, the pre-selecting of packages may also be a solution, such as selling valuable bands to one of the mobile operators instead of certain frequencies. The other two problems can be partially remedied by regulating the customers' possible bids according to certain activity rules. It is worth it therefore for the bidders making their initial bids in a similar way to their final bids, so that intermediate prices cannot mislead the other bidders. This was an innovation by Milgrom, which was already used in the 1994 procedure and later became common practice everywhere. 
Led by Milgrom, the FCC's 2017 spectrum auction was designed to respond to a special situation. Most of the earlier licensees of radio frequencies operated TV channels, but it became much more profitable to use the frequencies for mobile services. The task of the designers was to sell the frequencies purchased from the TV channel operators to the mobile operators. The procedure was proposed by Milgrom and others (Milgrom et al. 2012), and then the 2017 implementation was also done under their leadership (Milgrom - Segal 2017).

The essence of the procedure was that first a price was set in a reverse auction at which most TV operators were willing to sell their licenses. In parallel, the frequencies sold were auctioned to mobile operators in a forward auction in such a way as to generate an additional profit for the government from the price difference. However, it was also important to have the technological possibility to alter the bands of the service providers that retained their licenses, thus allowing the released frequencies to be provided in bands close to each other and with large area coverage to adequately meet the needs of the new mobile operators. This retuning led to an NP-hard graph colouring problem, where computer scientists also helped the organisers to efficiently solve the problem (Newman et al. 2017). The process was successful, with the state taking back licences amounting to about 10 billion US dollars from TV channels and selling them to mobile operators for about 20 billion. State intervention has, on the one hand, generated significant revenue and, on the other hand, successfully resolved the exchange of usage rights, which put the resources in the hands of the companies that utilise them most efficiently.

\subsection{Additional allocation applications}

As already mentioned, one area related to auctions is the organisation of matching mechanisms, where the difference is that payments are not allowed between participants. The basic matching algorithm for the university admission procedure was developed by Gale and Shapley (1962) in 1962. The admission system for secondary and higher education in Hungary is also based on this mechanism. Fifty years after the publication of this article, Roth and Shapley also received the Nobel Prize for their theoretical research in this field and for their participation in practical applications (Biró et al. 2013). The area of matching and auction mechanisms is covered together by the topic of market design. This is already taught in university courses as a separate field, for example by Milgrom at Stanford; we recommend the textbook on the subject by Haeringer (2018) to readers.

The fields of auctions and matchings are closely related. There are also models that can be said to be a common generalisation, such as the matching with contract model analysed by Hatfield and Milgrom (2005). In this, the parties to the pair can agree not only on the payment of money, but on any kind of contract. Under certain conditions, there always exist fair (also known as stable) solutions, and they form 
a lattice with two extreme solutions that are considered the best for all sellers and all buyers, respectively.

These results were already proven by Fleiner (2003) in an earlier paper on an even more general model, but Hatfield and Milgrom (2005) also showed that in the buyer-optimal solution, it is not worth manipulating the procedure individually by the buyers if certain monotonicity conditions are met. This result implies, among other things, the strategy-proofness of second-price auctions even for multi-object models, applicable for example also to keyword auctions conducted by Google (Aggarwal et al. 2009; Dütting et al. 2013).

In the following, we present two allocation applications where there is basically no payment, but with the introduction of tokens, essentially an artificial combinatorial auction procedure has been introduced in order to make the result fair and efficient.

\subsubsection{Distribution of food donations}

Feeding America is the largest aid organisation in the United States. Its most important task is to allocate the offered food to local food banks which distribute it to those in need. The distribution of donations raises a number of problems, in addition to logistical challenges, equity considerations are also involved, and ultimately the goal is to make the allocation efficient and to give the donations to those most in need. The allocation system has been drastically redesigned in recent years, as documented and analysed by Prendergast (2016).

In the previous system, food banks received offers for aid packages in a row, but these did not always meet their needs for quantitative or content reasons, since local needs may differ as charity organisations may also receive offers from other providers and local companies. The rejection of the offer, on the other hand, was a punishment: the food bank was left out of a round at that time, and this is why many times the package was accepted even if they could not distribute it ideally among those in need.

The new system is based on an artificial auction system where food banks receive tokens and can bid on aid packages on a daily basis. Under this system, they can make successful offers for packages of a quantity and content that can be put to good use by them. The system, which allows for a number of specialties, such as joint bidding, has proven very successful, with an annual increase in the total quantity of food allocated from 250 million pounds to 350 million pound in a short period of time. 


\subsubsection{Course allocation}

At Wharton College, a combinatorial auction-based course allocation system developed in recent years by Budish et al. (2017) has been introduced which also uses artificial money. Each student receives roughly 5,000 tokens that they can spend on enrolling in courses in an artificial auction powered by an optimisation algorithm.

Students can submit their valuations on each course at a value in between 0-100 which they can then refine into pairs of courses so that complementarities can appear in the evaluation. This is a compromise assuming total additivity - where the value of the course package is the sum of the values of the courses - which would be too simplistic, but if all course packages could be valuated, it would require students to evaluate an exponentially increasing number of packages, which is not feasible. Based on the value of the course packages, the goal of the optimisation algorithm is to calculate a competitive equilibrium, which means an object allocation and artificial prices at which each student receives the most valuable course package from their budget according to their given valuations. Such solution does not always exist for valuations involving complementarities, but a well-defined approximative solution can always be found, the theory of which was developed by Budish (2011).

In Hungary, almost every university uses the first-come-first-served course allocation mechanism which is a default setting in the central administrative system, called Neptun. Although it leads to a Pareto-efficient solution, it is very unfair and causes permanent stress for the students and the servers crash at the universities. The only alternative course allocation mechanism in Hungary is the priority-based system of Eötvös Loránd University, but it also has unavoidable flaws. The alternative based on the above combinatorial auction provides an efficient solution while being fair, as Budish proved that, for example, the solution fulfils the property that no student envies another student's course package after taking out a single course from it. This is a surprisingly strong property since it is impossible to give a solution without envy even with two students and a single course. For example, if there are two very good courses and two definitely worse courses for two students, then in Budish's solution it is guaranteed that each one of the students will get one of the good courses, while in the first-come-first-served solution both good courses will be obtained by the faster student.

\section{New interdisciplinary scientific areas}

The study of the functioning of markets was given a central role in Adam Smith's first book, from the beginning of economics. According to his intuition based on philosophical understanding, the market creates an equilibrium situation with the help of an invisible hand, which is shaped by the individual interests of the actors, 
but is still optimal for society. The exact mathematical proof of this statement is still the subject of articles showing the existence of such an optimal equilibrium situation in game theory models and the fact that self-interested actors can reach such a situation in a natural process (Chen et al. 2016; Biró et al. 2014). This market convergence can be very slow and costly in reality, even if it can be proved in more complex markets. Auctions are mechanisms that help the work of the invisible hand and accelerate it drastically, especially if supported by optimisation algorithms as well.

Game theory became well-known in the scientific research with the publication of the book by Neumann and Morgenstein (1944) and developed as part of mathematics and operations research in the 1960s. The initial theories applied to non-cooperative models, where participants acted according to their own interests throughout the game, with the goal of maximising individual benefit. Outstanding among the solution concepts is the Nash equilibrium, which means a choice of strategy and a related solution from which no player has an interest in deviating individually. Cooperative models have also emerged since the 1960s, which assume that groups of players can generate added value. The question here is what groups will work together and how they will share the extra benefits with each other (through payments or otherwise).

The basic toolbox for examining auctions is also represented by the game theory models, which were used by the Nobel laureates as well. In cooperative game theory, to study the market of sellers and buyers, the so-called assignment game (Shapley - Shubik 1971) and its generalisations represent the basic models, as mentioned earlier.

In the 1970s, mechanism design emerged as a branch of game theory for which Leonid Hurwicz, Eric Maskin and Roger Myerson were awarded the Nobel Prize in Economics in 2007. Here again, the goal is for participants who are considered rational and self-interested to achieve a fair and in some way optimal outcome in a given social or economic situation. The novelty in this is that the rules of the game and the procedure used can also be specified by the designer, who may also have an interest of his own, independent of the participants. In the case of spectrum auctions, for example, the central organiser, the government, apart from keeping the revenue level high, is also interested in having an efficient solution, i.e. that the winners can make good use of the acquired rights. The organiser is free to choose the auction procedure.

As part of the procedure, there may be also complex, direct functions in the mechanism. This means that the participants provide certain information (such as bids or selected packages for auctions) and, depending on these, the mechanism can move to the next decision point maybe after using a complex algorithm. 
It remains an important question whether a given mechanism can be manipulated by individual or group strategies. If so, the analysis of the final result should be conducted with extreme caution. But the fact that a mechanism is strategy-proof in theory does not mean that it will not be manipulated in practice, such as the deviation from real values in second-price auctions. Furthermore, the manipulable mechanism will not necessarily be manipulated by participants by giving false valuations in practical applications, as this may also involve a risk, i.e. an expected loss; and manipulation strategies in the Bayesian sense can also be calculable, where actors rationally maximise their expected utility through their decisions, and therefore the process can be well analysed and can lead to good results at the system level as well.

The development of algorithms and optimisation functions used in the mechanism requires the involvement of computer scientists, because there can be a theoretically correct and even strategy-proof procedure, it is with no avail if its exact computation is not possible quickly in a large market. In multi-object markets, computing optimal solutions can often lead to NP-hard problems for which no fast (polynomial runtime) algorithm can be expected. For this reason, for example, the VCG mechanism is often not feasible in practice, because in addition to determining the final allocation, accurate calculation of the optimal solutions in the sub-markets is required for pricing as well.

Because of these considerations, computer scientists have been involved in the design of many auction applications, and as a result, the above areas have also become interdisciplinary. Algorithmic game theory, algorithmic mechanism design, computational social choice, economics and computation are all areas that have developed in the last decade with their own journals and conferences, such as the 22nd ACM Economics and Computation Conference (http://ec21.sigecom.org/) planned to take place in July 2021 in Budapest. Here, the field of auctions is a main topic, and it is no coincidence that this conference series is regularly supported by companies such as Google, Facebook, Microsoft, Amazon, where auctions are designed by research teams of economists and computer scientists.

In some markets, such as spectrum allocation or the energy market, the solution must meet special technological requirements as well, so the involvement of engineers is also required for design. However, this is not the only reason why the two Nobel laureates listed the task of designing auctions as a new topic in market design and economic engineering. On the one hand, market designers need to have a wide range of theoretical knowledge in the fields of economics, game theory, mechanism design and computer science, building the market models on the laws of these fields of studies. In addition, in practice, it is often necessary to go beyond the framework provided by theory. The expected decisions of market participants need to be well estimated in the system, which can be aided by both 
practical observations and laboratory experiments, similarly to the observation and laboratory testing of the laws of physics, and the statistical analysis and scientific analysis of data can help in redesigning and fine-tuning market mechanisms including auctions or other matching mechanisms, similarly to how we can see the design and implementation process in the engineering sciences. An essential difference, however, always remains: market participants are not molecules or bearings, but those who make individual and group decisions that are often influenced by less rational, internal psychological reasons. This is dealt with more deeply in behavioural economics, and Richard $\mathrm{H}$. Thaler received the Nobel Prize in 2017 for his research in this area. But just as important is the information aggregated by groups and networks and the individual and collective decisions based on them, an area that also has a prominent Stanford expert, Matthew $O$. Jackson, who may be a future Nobel laureate.

\section{References}

Aggarwal, G. - Pál, D. - Muthukrishnan, S. - Pál, M. (2009): General auction mechanism for search advertising. Proceedings of the 18th International Conference on World Wide Web, Madrid, pp. 241-250.

Ausubel, L. M. - Milgrom, P. R. (2002): Ascending auctions with package bidding. The B.E. Journal of Theoretical Economics 1(1): 1-44.

Bichler, M. - Goeree, J.K. (2017): Handbook of spectrum auction design. Cambridge University Press.

Bichler, M. - Ferrell, D. - Fux, V. - Goeree, J.K. (2019): Designing Environmental Markets for Trading Catch Shares. INFORMS Journal on Applied Analytics, 49(5): 324-337. https:// doi.org/10.1287/inte.2019.1003

Biró, P. - Csóka, P. - Kóczy, Á.L. - Radványi, A. - Sziklai, B. (2013): Közgazdasági Nobelemlékdíj 2012 (2012 Nobel Memorial Prize in Economic Sciences). Magyar Tudomány, 174(2): 190-199.

Biró, P. - Bomhoff, M. - Golovach, P.A. - Kern, W. - Paulusma, D. (2014): Solutions for the stable roommates problem with payments. Theoretical Computer Science, 540-541: 53-61. https://doi.org/10.1016/j.tcs.2013.03.027

Budish, E. - Cachon, G.P. - Kessler, J.B. - Othman, A. (2017): Course match: A largescale implementation of approximate competitive equilibrium from equal incomes for combinatorial allocation. Operations Research, 65(2): 314-336. https://doi.org/10.1287/ opre.2016.1544

Budish, E. (2011): The combinatorial assignment problem: Approximate competitive equilibrium from equal incomes. Journal of Political Economy, 119(6): 1061-1103. https:// doi.org/10.1086/664613 
Chen, B. - Fujishige, S. - Yang, Z. (2016): Random decentralized market processes for stable job matchings with competitive salaries. Journal of Economic Theory, 165: 25-36. https:// doi.org/10.1016/j.jet.2016.04.003

Clarke, E.H. (1971): Multipart pricing of public goods. Public Choice, 11: 17-33. https://doi. org/10.1007/BF01726210

Dütting, P. - Henzinger, M. - Weber, I. (2013): Sponsored search, market equilibria, and the Hungarian Method. Information Processing Letters, 113(3): 67-73. https://doi. org/10.1016/j.ipl.2012.11.006

Edelman, B. - Ostrovsky, M. - Schwarz, M. (2007): Internet advertising and the generalized second-price auction: Selling billions of dollars worth of keywords. American Economic Review 97(1): 242-259. https://doi.org/10.1257/aer.97.1.242

Fleiner, T. (2003): A fixed-point approach to stable matchings and some applications. Mathematics of Operations Research, 28(1): 103-126.

Fox, J.T. (2018): Estimating matching games with transfers. Quantitative Economics, 9(1): 1-38. https://doi.org/10.3982/QE823

Groves, T. (1973): Incentives in teams. Econometrica: Journal of the Econometric Society, 41(4): 617-631. https://doi.org/10.2307/1914085

Gale, D. - Shapley, L.S. (1962): College admissions and the stability of marriage. The American Mathematical Monthly, 69(1): 9-15. https://doi.org/10.2307/2312726

Haeringer, G. (2018): Market design: auctions and matching. MIT Press.

Hatfield, J.W. - Milgrom, P.R. (2005): Matching with Contracts. American Economic Review, 95(4): 913-935. https://doi.org/10.1257/0002828054825466

Kácsor, E. (2021): Modelling Bidding Behaviour on German Photovoltaic Auctions. Energies 2021, 14(2), 516. https://doi.org/10.3390/en14020516

Kagel, J.H. - Lien, Y. - Milgrom, P. (2010): Ascending prices and package bidding: A theoretical and experimental analysis. American Economic Journal: Microeconomics, 2(3): 160-185. https://doi.org/10.1257/mic.2.3.160

Koopmans, T.C. - Beckmann, M. (1957): Assignment problems and the location of economic activities. Econometrica, 25(1): 53-76.

Krishna, V. (2002): Auction Theory. 1st Edition. Elsevier. https://EconPapers.repec.org/ RePEc:eee:monogr:9780124262973

Magyarkuti, Gy. (2018): Aukcióelmélet elöadások. Corvinus University of Budapest. https:// doi.org/10.14267/cb.2018k02

Milgrom, P. - Ausubel, L. - Levin, J. - Segal, I. (2012): Incentive auction rules option and discussion. Report for Federal Communications Commission. September 12. 
Milgrom, P. (2000): Putting auction theory to work: The simultaneous ascending auction. Journal of Political Economy, 108(2): 245-272. https://doi.org/10.1086/262118

Milgrom, P. (2004): Putting Auction Theory to Work. Cambridge Books, Cambridge University Press. https://doi.org/10.1017/CBO9780511813825

Milgrom, P. - Segal, I. (2017): Designing the US Incentive Auction. In: Bichler, M. - Goeree, J. (eds.): Handbook of Spectrum Auction Design. Cambridge: Cambridge University, pp. 803-812. https://doi.org/10.1017/9781316471609.038

Milgrom, P.R. - Weber, R.J. (1982): A Theory of Auctions and Competitive Bidding. Econometrica, 50(5): 1089-1122. https://doi.org/10.2307/1911865

Monostori, Z. (2013): Diszkriminativ áras és egyenáras aukciók (Discriminatory price and uniform price auctions). Közgazdasági Szemle (Economic Review), 60(10): 1048-1074.

Neumann, L.J. - Morgenstern, O. (1944): Theory of games and economic behaviour. Vol. 60. Princeton University Press.

Newman, N. - Fréchette, A. - Leyton-Brown, K. (2017): Deep optimization for spectrum repacking. Communications of the ACM 61(1): 97-104. https://doi.org/10.1145/3107548

Nobel Prize Committee (2020): Improvements to auction theory and inventions of new auction formats. Nobel Prize in Economics documents 2020-2. Nobel Prize Committee. https://ideas.repec.org/p/ris/nobelp/2020_002.html

Prendergast, C. (2016): The Allocation of Food to Food Banks. EAI Endorsed Trans. Serious Games, 16(10): e4. https://doi.org/10.4108/eai.8-8-2015.2261169

Shubik, M. (2004): The Theory of Money and Financial Institutions: Volume 1. The MIT Press.

Shapley, L.S. - Shubik, M. (1971): The assignment game I: The core. International Journal of game theory, 1(1): 111-130.

Varian, H.R. - Harris, C. (2014): The VCG auction in theory and practice. American Economic Review, 104(5): 442-445. https://doi.org/10.1257/aer.104.5.442

Vickrey, W. (1961): Counterspeculation, auctions, and competitive sealed tenders. The Journal of Finance 16(1): 8-37. https://doi.org/10.1111/j.1540-6261.1961.tb02789.x

Wilson, R. (1979): Auctions of shares. The Quarterly Journal of Economics, 93(4): 675-689. https://doi.org/10.2307/1884475

Wilson, R. (2002): Architecture of power markets. Econometrica, 70(4): 1299-1340.

Wilson, R. (2008): Supply function equilibrium in a constrained transmission system. Operations research, 56(2): 369-382. https://doi.org/10.1287/opre.1070.0421 